\title{
Titanium Dioxide Thin Films with Controlled Stoichiometry for Photoelectrochemical Systems
}

\author{
M. RADECKA, ${ }^{1,4}$ A. BRUDNIK, ${ }^{2}$ K. KULINOWSKI, ${ }^{3}$ A. KOT, ${ }^{1}$ \\ J. LESZCZYŃSKI ${ }^{1}{ }^{\mathrm{J}}$. KANAK, ${ }^{2}$ and K. ZAKRZEWSKA ${ }^{2}$ \\ 1.-Faculty of Materials Science and Ceramics, AGH University of Science and Technology, Al. A. \\ Mickiewicza 30, 30-059 Kraków, Poland. 2.-Faculty of Computer Science, Electronics and \\ Telecommunications, AGH University of Science and Technology, Al. A. Mickiewicza 30, 30-059 \\ Kraków, Poland. 3.-Faculty of Physics and Applied Computer Science, AGH University of \\ Science and Technology, Al. A. Mickiewicza 30, 30-059 Kraków, Poland. 4.-e-mail: \\ radecka@agh.edu.pl
}

\begin{abstract}
The electrical resistivity of thin film metal oxide photoanodes in the photoelectrochemical cells, PEC, for hydrogen generation, the importance of which should not be neglected in the design and construction of water-splitting devices, is found to be affected by the departure from stoichiometric composition and film thickness. Here, we propose to use $\mathrm{TiO}_{2} / \mathrm{ITO}$ photoanodes for photoelectrochemical cells. The $\mathrm{TiO}_{2-x}$ thin films with $x$ indicating a departure from the stoichiometric composition have been prepared by dc magnetron sputtering with the deposition rate controlled by the optical emission spectroscopy, OES. Photoanode properties were determined by scanning electron microscopy, SEM, atomic force mocroscopy, AFM, Raman spectroscopy, transmittance and reflectance measurements over uv/vis/nir wavelength ranges, impedance spectroscopy, Mott-Schottky plots, and photocurrent versus voltage dependence in the dark and under white light illumination. The contributions of the charge carrier concentration and mobility to the enhanced photocurrent of the PEC have been determined and correlated to the varying film stoichiometry and thickness, respectively.
\end{abstract}

Key words: $\mathrm{TiO}_{2}$, thin films, electrical resistivity, ITO

\section{INTRODUCTION}

Photoelectrochemical systems designed for hydrogen generation have been developed since the first realization in 1972 that efficient and reproducible photodecomposition of water could be carried out with the use of an auxiliary semiconducting photoanode such as $\mathrm{TiO}_{2} \cdot{ }^{1}$ Since that time, enormous efforts and money have been dedicated to make this particular application of $\mathrm{TiO}_{2}$ successful. ${ }^{2-13} \mathrm{As}$ a result of all these attempts, integrated solar-driven water-splitting devices have been developed and tested for hydrogen production on a laboratory scale. ${ }^{14-19}$ Although, these experimental devices

(Received February 12, 2019; accepted April 30, 2019;

published online May 16, 2019) have entered the stage of commercialization, their mass fabrication has not been reached. The reason for that should be sought for in the properties of available photoanode materials and can be related to inefficient solar energy-to-hydrogen conversion processes.

An integrated solar-driven water-splitting device is generally comprised of light absorbers, electrocatalysts, membrane separators, and an electrolyte solution in a given system geometry. ${ }^{15}$ Metal oxide photoanode that acts as a photon hv absorber and catalyst of reaction:

$$
2 h v+\mathrm{H}_{2} \mathrm{O} \rightarrow 1 / 2 \mathrm{O}_{2}(\text { gas })+\mathrm{H}_{2}(\text { gas })
$$

is one of the most important elements of the device. In order to generate oxygen and hydrogen by this process (Eq. 1), a thermodynamic potential of 
$1.23 \mathrm{eV}$ is required. ${ }^{1}$ As water is transparent to light over this wavelength range, the photons of at least $1.23 \mathrm{eV}(\lambda<1000 \mathrm{~nm})$ should be absorbed by a semiconductor photoanode to generate electrons and holes in the respective conduction $\mathrm{CB}$ and valence VB bands:

$$
h v \rightarrow e^{\prime}+h
$$

Therefore, the band gap energy of a semiconductor should be higher than $1.23 \mathrm{eV}$ or even in between $1.8 \mathrm{eV}$ and $2.4 \mathrm{eV}$ taking into account all possible losses. ${ }^{4,6,20}$ In order to run effectively the process of water splitting, the band edges of the semiconductor photoanode should fulfill the following condition: $E_{\mathrm{H}+/ \mathrm{H} 2}^{\mathrm{o}}<E_{\mathrm{CB}}$ and $E_{\mathrm{O} 2 / \mathrm{H} 2 \mathrm{O}}^{\mathrm{o}}>\mathrm{E}_{\mathrm{VB}}$. In spite of the fact that $\mathrm{TiO}_{2}$ meets both these conditions, its main drawback is too wide a band gap which results in poor utilization of the solar spectrum and low solar energy-to-hydrogen conversion efficiency. ${ }^{1,3,6}$

Although at least four generations of photoanodes based on titania have been proposed, ${ }^{4,5,21-23}$ there is still a limited success of this specific photoanode material. The first generation was based on undoped anatase/rutile and non-stoichiometric titanium dioxide. The next three generations of photoanode materials involved doping of either cationic (second generation), anionic (third generation) or both (fourth generation) sublattices.

However, there is one aspect, usually neglected, that should have a significant influence on the behaviour of the integrated solar-driven watersplitting device, which is an electrical resistance of the $\mathrm{TiO}_{2}$ photoanode deposited on the substrate. In the case of transparent and conductive oxide substrates TCO, it is the resistance of the system: $\mathrm{TiO}_{2}$ layer + TCO substrate that should be taken into account.

Electrical properties of $\mathrm{TiO}_{2}$ thin films have been discussed in many papers. ${ }^{24-35}$ It has been noted that the electrical resistivity is related to the sample non-stoichiometry. ${ }^{34}$ Oxygen vacancies in the case of non-stoichiometric thin films of $\mathrm{TiO}_{2-\mathrm{x}-}$ are responsible for an increased charge carrier concentration.

However, as recently discussed, ${ }^{35}$ much more attention should be paid to the charge carrier mobility. Widely-expanded opinion about very low electron mobility $\left(<1 \mathrm{~cm}^{2} \mathrm{~V}^{-1} \mathrm{~s}^{-1}\right.$ at room temperature) due to an extremely large effective mass within the range $30-100 \mathrm{~m}_{\mathrm{e}}{ }^{24}$ has been recently verified. Dorow-Gerspach and Wuttig in their last paper $^{33}$ reported much higher electron mobility of $15 \mathrm{~cm}^{2} \mathrm{~V}^{-1} \mathrm{~s}^{-1}$ for stoichiometric thin films of crystalline anatase $\mathrm{TiO}_{2}$ obtained by reactive magnetron sputtering. Significant drop in the electron mobility to $0.06 \mathrm{~cm}^{2} \mathrm{~V}^{-1} \mathrm{~s}^{-1}$ upon decreasing relative oxygen level $\mathrm{O}_{2 \text { PP }}$ below $55 \%$ has been attributed to the crystallographic disorder related to the amorphous phase formation.

We believe, that well-crystallized $\mathrm{TiO}_{2}$ providing good electron mobility should play the most important role in the photoelectrochemical applications.

The motivation for the present study was to develop a clear description of the role the electrical resistivity of the $\mathrm{TiO}_{2} / \mathrm{TCO}$ photoanode plays in photoelectrochemical water-splitting. Here, commercially available ITO substrates have been used as supports for thin films of $\mathrm{TiO}_{2-x}$ with controlled departure from stoichiometry. Thin films of $\mathrm{TiO}_{2-\mathrm{x}}$ have been obtained by dc reactive sputtering from the $\mathrm{Ti}$ target in the $\mathrm{Ar}+\mathrm{O}_{2}$ atmosphere. The plasma emission controlled system provided reproducibility of the deposition conditions as far as the departure from stoichiometry was concerned. Variation of the film parameters such as their thickness and stoichiometry has been correlated with the morphology, crystallographic structure, optical and electrical properties with a special emphasis on the photoelectrochemical responses to illumination.

\section{EXPERIMENTAL}

\section{Thin Film Deposition}

Titanium oxide thin films were deposited onto specified substrates (amorphous silica a-SiO ${ }_{2}$, indium tin oxide ITO, glass and $\mathrm{Si}$ ) using a home built DC magnetron system. ${ }^{36}$ The pure $(5 \mathrm{~N})$ titanium disc of $90 \mathrm{~mm}$ in diameter has been used as a sputtering target. The magnetron discharge was driven by dc-pulse power supply, working as a current source. ${ }^{37}$ The distance between the target and substrate holder was kept at $50 \mathrm{~mm}$. The substrates were heated before and during the film growth at the temperature of $250^{\circ} \mathrm{C}$. High purity argon $(6 \mathrm{~N})$ and oxygen $(5 \mathrm{~N})$ were used as the sputtering and reactive gases, respectively. Gas flows were controlled by mass flow controllers. The base pressure of the system better than $5 \times 10^{-6}$ mbar was attained with the turbomolecular pump. Sputtering was performed at a total pressure of $1 \times 10^{-2}$ mbar. Magnetron current was stabilized at $2 \mathrm{~A}$ with the sputtering power varying between $0.9 \mathrm{~kW}$ and $1.0 \mathrm{~kW}$.

Optical emission spectroscopy (OES) ${ }^{38}$ was used for controlling the deposition rate in order to stabilize the operating mode of sputtering. The optical emission of $\operatorname{Ti}(\lambda=500 \mathrm{~nm})$ line intensity in the pure argon discharge (no flow of oxygen) was used as a reference for monitoring the OES system.

The oxygen flow was controlled by setting the current titanium emission line intensity at a predefined value. The ratio $I / I_{0}$ correlates with the sputtering rate ran $^{2,39,40}$ and corresponds to the deviation from stoichiometry $x$ in $\mathrm{TiO}_{2-x}$. Higher 
$I / I_{0}$ indicates more oxygen deficient compositions as shown in Ref. 41.

\section{Techniques Employed for Determination of the Photoanode Properties}

The thickness of the deposited thin films was measured by a Talystep (Rank Taylor Hobson) stylus profilometer. The scanning electron microscope SEM morphological studies were carried out using Nova NanoSem 200 instrument equipped with an energy dispersive $\mathrm{x}$-ray spectroscope.

The surface morphology was studied with an atomic force microscope (AFM) in semi-contact mode using a NTEGRA Aura-NT-MDT system. Root mean square (RMS) was calculated.

Raman spectra were collected using Witec Alpha $300 \mathrm{M}+$ spectrometer equipped with $100 \times$ objective and 1800 grating. Incident light excitation at the wavelength of $488 \mathrm{~nm}$ was provided by a laser. Raman spectra were recorded upon two accumulations within the range of wavenumbers extending from $1 \mathrm{~cm}^{-1}$ to $4000 \mathrm{~cm}^{-1}$.

Transmittance and reflectance spectra of ITO, $\mathrm{TiO}_{2}^{\prime} \mathrm{ITO}$ and $\mathrm{TiO}_{2} / \mathrm{a}-\mathrm{SiO}_{2}$ were measured by a Perkin Elmer Lambda 19 spectrophotometer within the wavelength range of $220-2500 \mathrm{~nm}$.

Impedance spectroscopy data were acquired by means of the dielectric interface Solartron 1296 and frequency response analyser Solartron 1260. Two different configurations were tested. The impedance measurements to determine the electrical resistance were performed over the frequency range of $1-10^{6} \mathrm{~Hz}$ at room temperature. Two gold point electrodes separated by a distance of $10 \mathrm{~mm}$ were applied. Moreover, the capacitance of the electrode/electrolyte interface as a function of the voltage in the photoelectrochemical cell PEC was studied using the same equipment (Solartron 1260 + Solartron 1296). In this case, the measurements were performed in the dark at a constant frequency of $10 \mathrm{kHz}$. Analysis of the impedance spectra was carried out with the help of the ZPLOT software provided by Solartron and dedicated for this purpose.

\section{Functional Measurements: Photocurrent Versus Applied Voltage}

Photoelectrochemical experiments in the dark and under illumination were performed in a custom-made photoelectrochemical cell PEC. A threeelectrode cell was employed, with the working anode based on $\mathrm{TiO}_{2}$ /ITO thin films, a saturated calomel electrode (SCE) as a reference electrode, and a $\mathrm{Pt}$ foil covered with a Pt black acting as a cathode. A $\mathrm{Na}_{2} \mathrm{SO}_{4}$ solution $(0.8 \mathrm{M}, \mathrm{pH}=6.25)$ was used as the electrolyte. The PEC was illuminated with a white light provided by a $450 \mathrm{~W}$ Xe lamp. An ANKO potentiostat was used for the current-voltage measurements.

\section{RESULTS AND DISCUSSION}

Optical and electrical characterizations of ITO substrates have been performed, and the results of the analysis are shown in Fig. 1.

The ITO substrate exhibits high transparency within the wavelength range of 400-1000 $\mathrm{nm}$ and high reflectivity in the infrared IR region (Fig. 1a). From the region of the fundamental absorption edge, the band gap of ITO has been determined to be of about $4.11 \mathrm{eV}$ in accordance with the literature data. ${ }^{42-44}$ High concentration of electrons results in the plasma reflectance edge quite clearly seen in the near infrared as an abrupt increase in reflectance coefficient $R$ accompanied by a decrease in the transmittance $T$. Interaction of light with the electron cloud can be understood on the basis of the classical Drude's model. ${ }^{45}$

The plasma resonance wavelength $\lambda_{\mathrm{p}}$ was obtained as a cutoff wavelength, at which $T\left(\lambda_{\mathrm{p}}\right)=$ $R\left(\lambda_{\mathrm{p}}\right)$. Under these conditions, the dielectric-like visible transmittance is the same as the metalliclike IR reflectance.

The plasma resonance frequency $\omega_{\mathrm{p}}$ is given by

$$
\omega_{\mathrm{p}}^{2}=\frac{N e^{2}}{\varepsilon_{0} \varepsilon_{\infty} m^{*}},
$$

where $\varepsilon_{\infty}$ and $\varepsilon_{0}$ represent the dielectric constants of the ITO and a free space, respectively, $m^{*}$ is the effective mass of the charge carriers, and $N$ is the carrier concentration.

The relationship between the plasma resonance wavelength $\lambda_{\mathrm{p}}$ and plasma resonance frequency $\omega_{\mathrm{p}}$ is given as:

$$
\lambda_{\mathrm{p}}=\frac{1240}{\hbar \omega_{\mathrm{p}}}=\frac{1240}{h v_{\mathrm{p}}}
$$

where $\omega_{\mathrm{p}}=v_{\mathrm{p}} \cdot 2 \pi$ and the photon energy $h v_{\mathrm{p}}$ is expressed in $\mathrm{eV}$.

For ITO it was assumed that $\varepsilon_{\infty}=4, m^{*}=0.3 m_{0}$, while plasma resonance wavelength was calculated as $\lambda_{\mathrm{p}}=1380 \mathrm{~nm}$ which corresponds to $h v_{\mathrm{p}}=0.90 \mathrm{eV}$.

The charge carrier concentration computed from (3) has been found to be $N=7.02 \times 10^{20} \mathrm{~cm}^{-3}$, which remains within the limits of the literature data. ${ }^{43,44}$

Further characterization of ITO was carried out by means of the electrical measurements of MottSchottky plots $C^{-2}$ versus $V_{\mathrm{B}}$, impedance spectroscopy $|Z|$ versus $f$ or admittance $Y^{\prime \prime}$ (imaginary part) versus $Y^{\prime}$ (real part), current $I$-voltage $V_{\mathrm{B}}$ as well as photoelectrochemical measurements of current $I$ versus voltage $V_{\mathrm{B}}$ in dark and under white light illumination. The results of these investigations are shown in Fig. 1b-e.

The electrical resistance of the ITO substrate has been determined from the Mott-Schottky plots to be of about $22.5 \Omega$ independently of the applied voltage. The same conclusion could be drawn from the linearity of $I-V$ characteristics indicating ohmic 

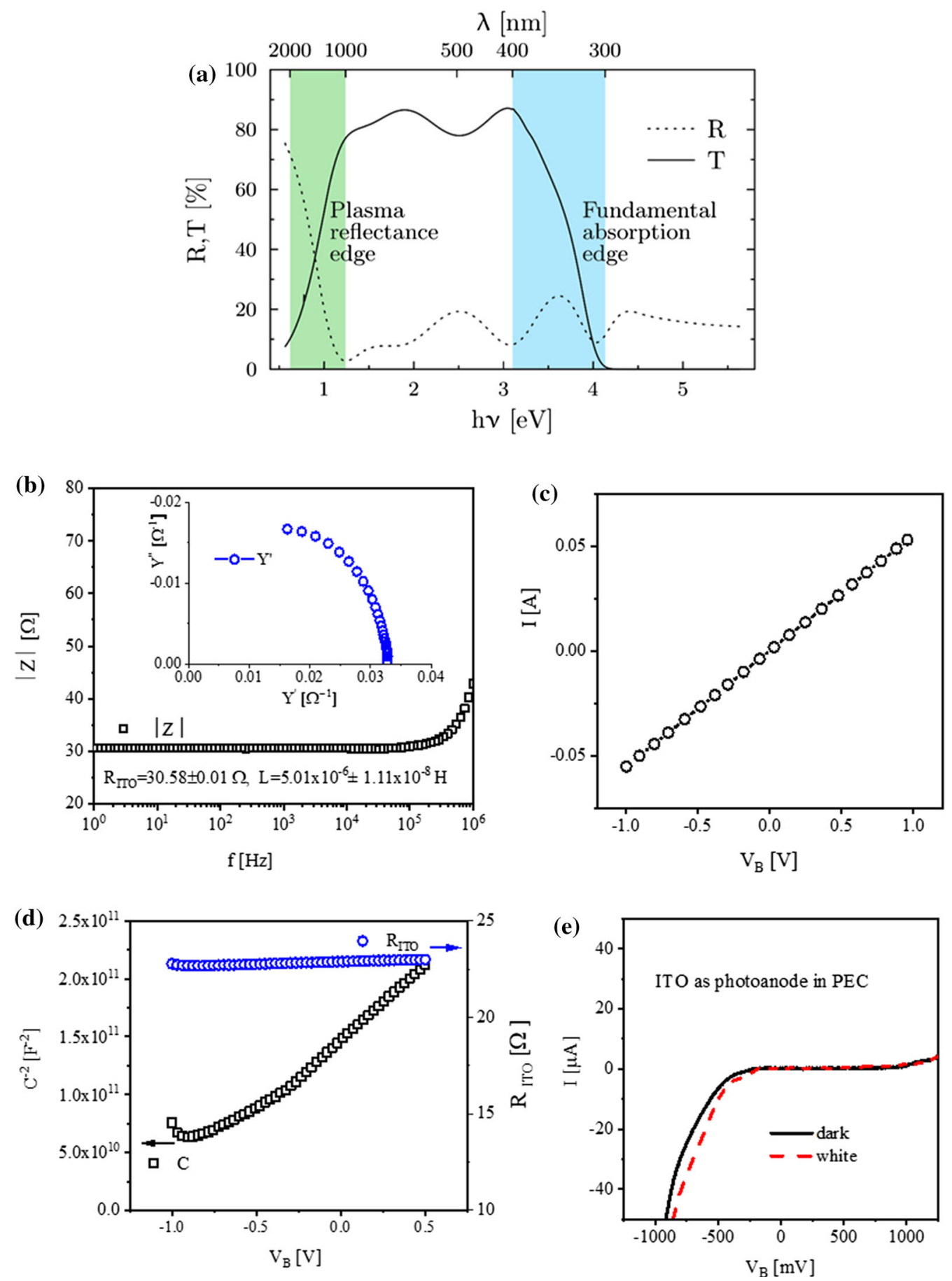

Fig. 1. Optical and electrical characterization of the ITO substrate; transmittance $T$ and reflectance $R$ spectra (a), impedance spectra: $|Z|-$ absolute value of the impedance; $f$-frequency, $Y^{\prime}$-real, $Y^{\prime \prime}$-imaginary parts of the admittance. The inset shows Nyquist plot (b) $I-V_{B}$ characteristics (c), Mott-Schottky plot and resistance of ITO versus applied voltage $V_{\mathrm{B}}(\mathrm{d})$ and current versus voltage dependence for PEC with a photoanode based on ITO (e).

behaviour of the ITO electrode. A quite similar result has been obtained from the impedance spectra that could have been fitted with a simple equivalent circuit consisting of a resistor of about $30 \Omega$ and an inductance of about $5 \mu \mathrm{H}$.

As far as the carrier concentration is concerned, its value derived from the Mott-Schottky plots is of about $1.4 \times 10^{21} \mathrm{~cm}^{-3}$ which is almost of the same order of magnitude as that determined from the plasma reflectance edge, Eq. 3.

From the $I-V_{\mathrm{B}}$ plots in dark and under illumination, performed in the three-electrode photoelectrochemical cell described in the experimental subsection "Functional Measurements: Photocurrent 
Versus Applied Voltage", it can be concluded that the ITO substrate is suitable for the construction of the more complex electrodes especially for $\mathrm{TiO}_{2} / \mathrm{ITO}$ photoanodes. In this case, both the anodic part of photocurrent and the dark current are close to zero, therefore, we make sure that the ITO substrate does not contribute to the processes of water splitting in the PEC device.

The Raman spectra of the $\mathrm{TiO}_{2} / \mathrm{ITO}$ photoanodes (Fig. 2) allow us to study their structural properties from the point of view of polymorphic forms crystallizing under oxidizing $\left(I / I_{0}=0.16\right)$ and slightly under-oxidized $\left(I / I_{0}=0.20\right)$ conditions of the film growth. In all these cases, only the anatase form can be distinguished which manifests itself by the presence of five characteristic Raman peaks at $144 E_{\mathrm{g}(1)}, \quad 196 E_{\mathrm{g}(2)}, \quad 396 B_{1 \mathrm{~g}(1)}, \quad 516 A_{1(\mathrm{~g})}$, and $638 E_{\mathrm{g}(3)} \mathrm{cm}^{-1}$. ${ }^{46}$ The tendency towards amorphisation is clearly seen in the case of slightly nonstoichiometric $\mathrm{TiO}_{2-x}$ obtained at $I / I_{0}=0.20$ where only the $144 \mathrm{~cm}^{-1}$ Raman peak can be distinguished. Moreover, the influence of $\mathrm{TiO}_{2}$ film thickness on the structure ordering is clearly seen. Higher thickness of stoichiometric films obtained at $I / I_{0}=0.16$ results in better crystallization of anatase polymorphic form. Under these growth conditions we do not expect rutile to be present. ${ }^{2}$

Figure 3 presents SEM images of the top surface of ITO substrates and $\mathrm{TiO}_{2} / \mathrm{ITO}$ photoanodes at different magnifications. Typical morphology of transparent conductive metal oxide is clearly demontrated in the case of ITO. The grains visible in scanning electron micrographs are small with a diameter of about $30 \mathrm{~nm}$. Very thin films $(d=50 \mathrm{~nm})$ of stoichiometric $\mathrm{TiO}_{2}$ follow the pattern imposed by ITO. However, larger film thickness $(d=280 \mathrm{~nm})$ allows one to observe the morphology characteristic for $\mathrm{TiO}_{2}$. The $\mathrm{TiO}_{2}$ forms a dense layer composed of nano-agglomerates.

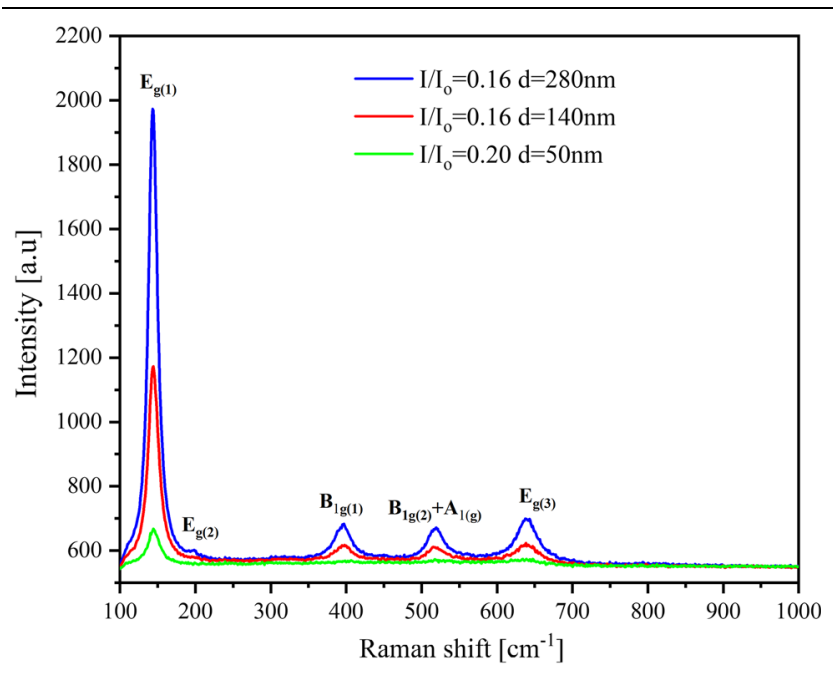

Fig. 2. Raman spectra for $\mathrm{TiO}_{2} / \mathrm{ITO}$ photoanodes.
AFM images (Fig. 4) of bare ITO substrate and $\mathrm{TiO}_{2}$ thin films of different thickness deposited on ITO confirm the conclusions drawn from SEM (Fig. 3). The roughness of ITO substrate (RMS = $3.230 \mathrm{~nm})$ is reduced to $\mathrm{RMS}=2.347 \mathrm{~nm}$ when covered by a very thin film of $\mathrm{TiO}_{2}(d=50 \mathrm{~nm})$. For thicker $\mathrm{TiO}_{2}$ films $(d=280 \mathrm{~nm})$ the surface roughness increases to RMS $=2.832 \mathrm{~nm}$ because of the pronounced influence of the columnar film growth.

Optical properties of $\mathrm{TiO}_{2} / \mathrm{ITO}$ photoanodes have been studied by analyzing the transmittance $T(\lambda)$ and reflectance $R(\lambda)$ spectra over the wide wavelength range extending from the ultraviolet to near infrared region as shown in Fig. 5a. However, as the optical properties of the ITO substrate dominate the optical spectra of $\mathrm{TiO}_{2} / \mathrm{ITO}$, which manifest itself in the plasma reflectance edge and the interference fringes observed in both $T(\lambda)$ and $R(\lambda)$, it was necessary to deposit $\mathrm{TiO}_{2}$ on featureless substrate such as an amorphous silica a-SiO ${ }_{2}$ (Fig. 5b). For a very thin stoichiometric $\mathrm{TiO}_{2}$ film one can observe the fundamental absorption edge extending from $300 \mathrm{~nm}$ to $400 \mathrm{~nm}$ which corresponds to the band gap of anatase of about 3.2-3.4 eV. The values of the band gap $E_{\mathrm{g}}$ for $\mathrm{TiO}_{2}$ (Table I) thin films of variable thickness and stoichiometry differ from those reported for crystalline anatase, which is due to the nanocrystalline nature of the films obtained. Very thin, stoichiometric films of $\mathrm{TiO}_{2}$ reach very high transmittance coefficients in the near infrared, $T(\lambda=2200 \mathrm{~nm})=90 \%$ while the reflectance coefficient is very low, $R(\lambda=2200 \mathrm{~nm})=10 \%$ which indicates no light absorption. Due to a very high refractive index of $\mathrm{TiO}_{2}, n>2.2$, the reflectance coefficient is quite elevated in the visible range of the light spectrum ( $R=40 \%$ for $400 \mathrm{~nm}<\lambda<500 \mathrm{~nm})$. Moreover, even at this small thickness $d=50 \mathrm{~nm}$, the wavelength modulation in $T$ and $R$ attributed to the light interference, is clearly seen.

Impedance spectra for $\mathrm{TiO}_{2} / \mathrm{ITO}$ photoanodes in Nyquist and Bode configurations are given in Fig. 6. The spectra demonstrate a typical semiconducting behavior, thus they have been fitted with an equivalent circuit consisting of the electrical resistor and capacitance elements in series. Small capacitance $C$ of $\mathrm{TiO}_{2}$ of the order of $10^{-11} \mathrm{~F}$ is characteristic for dielectric processes taking place in this material. The electrical resistance decreases systematically with the increasing film thickness. The electrical resistivity $\rho$ as a function of the films thickness and stoichiometry, given in Table I, has been determined from the impedance spectra.

It should pointed out at this stage that it is impossible from these data to assess the contributions of charge carrier concentration $N$ and mobility $\mu$ to the electrical resistivity. This could be done if the charge carrier concentration were derived from independent measurements of, for example, Mott-Schottky plots (Fig. 7a). From the slope of $C^{-2}$ versus $V_{\mathrm{B}}$ dependence the concentration of the charge carriers can be calculated according to the formula: 


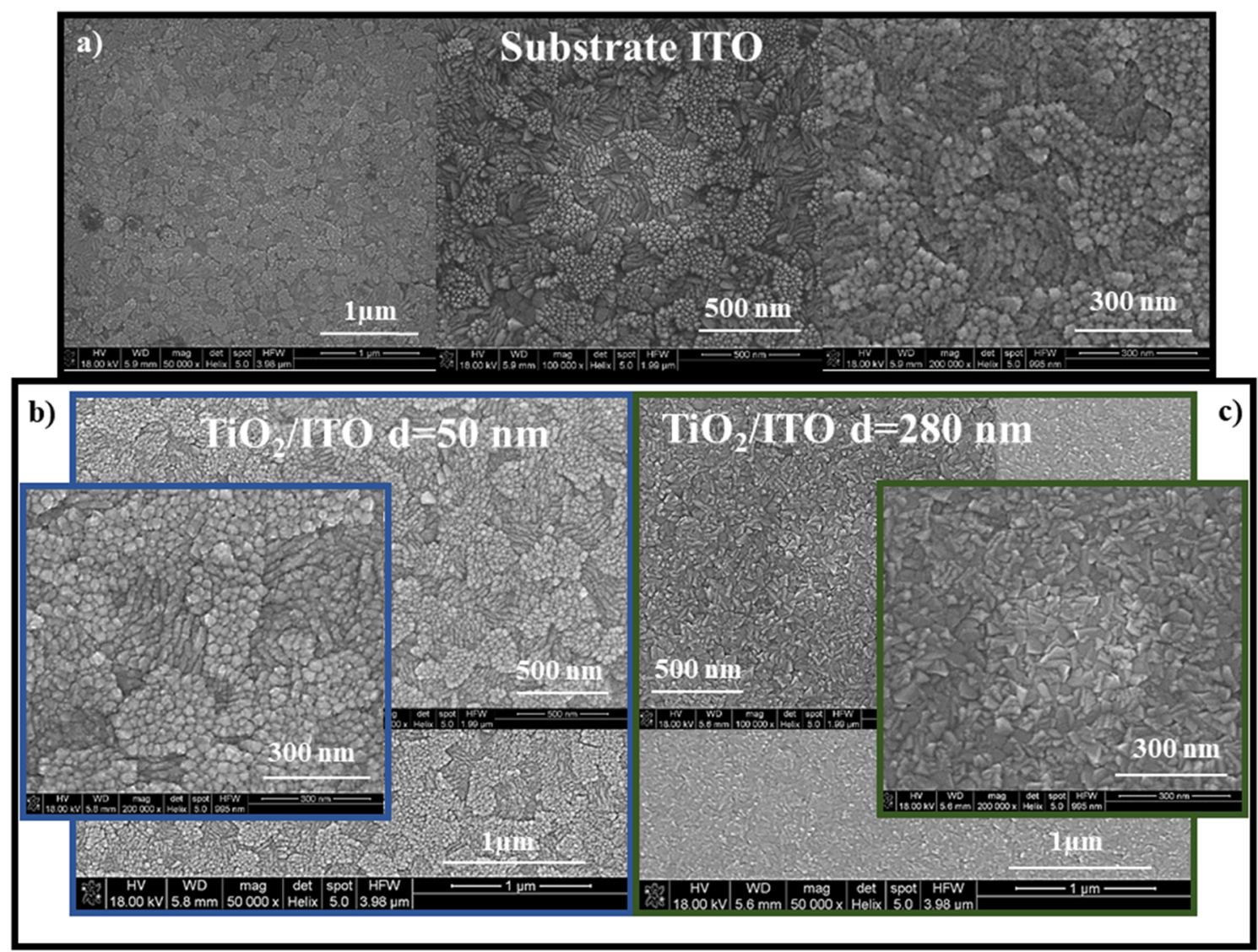

Fig. 3. SEM top surface images of ITO substrate (a) and $\mathrm{TiO}_{2} / \mathrm{ITO}$ photoanodes: thin film thickness $d=50 \mathrm{~nm}$ (b) and $d=280 \mathrm{~nm}(\mathrm{c})$.

$$
C_{\mathrm{SC}}^{-2}=\left(\frac{2}{\varepsilon \varepsilon_{0} e N S^{2}}\right)\left(V_{\mathrm{B}}-V_{\mathrm{FB}}-\frac{k T_{\mathrm{A}}}{e}\right),
$$

where $T_{\mathrm{A}}$ is the absolute temperature, $k$ is the Boltzmann constant, $S=1 \mathrm{~cm}^{2}$ is an area of the electrode.

The positive slope of $C^{-2}$ versus $V_{\mathrm{B}}$ for $\mathrm{TiO}_{2} / \mathrm{ITO}$ photoanodes indicates the $n$-type conductivity of deposited $\mathrm{TiO}_{2}$ thin films. The results of $N$ calculations are included in Table I.

The current-voltage characteristics for $\mathrm{TiO}_{2} / \mathrm{ITO}$ photoanodes shown in Fig. 7b prove that this electrode fulfills the requirements for a correct performance of the photoelectrochemical cell, PEC. The dark current is small, the cathodic current is negative while the anodic photocurrent is positive and much higher than the dark current in this configuration. The flat band $V_{\mathrm{FB}}$ potential determined as a photocurrent onset (see Fig. 7b) is negative for all photoanodes discussed in this work.

There are numerous experimental methods of the flat band potential estimation. They include: illuminated OCP (open circuit potential), Mott-Schottky analysis without illumination and the photocurrent onset. However, due to certain limitations of each technique, the values of $V_{\mathrm{FB}}$ resulting from these different methods can be in some disagreement. From the Mott-Schottky plot, the flatband potential $V_{\mathrm{FB}}$ can be obtained as the intercept of $(C)_{-2}$ with the $\mathrm{V}_{\mathrm{B}}$-axis.

The values of the flat band potential obtained from the Mott-Schottky plots are also included in Table I. Comparing them with the flat band potential determined from the photocurrent only, one can see that $V_{\mathrm{FB}}$ shifts towards more negative values. The photocurrent onset is the method based on the fact that upon photogeneration of the electron-hole pairs in the semiconductor, the bands become less bent. In the vicinity of flat band potential $V_{\mathrm{FB}}$ the recombination process may suppress the photocurrent. In fact, the measured capacitance does not necessarily correspond to the exact value of the space charge capacitance $C_{\mathrm{sc}}$ due to the contribution of other capacitances such as that of the Helmholtz layer, the Gouy layer, surface states, deep donor levels, and dielectric relaxation. Therefore, it would be advantageous to use an alternative method to check the value of $V_{\mathrm{FB}}$ derived from the capacitance potential studies.

The influence of stoichiometry and thickness of $\mathrm{TiO}_{2}$ thin films on the $V_{\mathrm{FB}}$ can be seen in Table I. As a general rule, stoichiometric thin films, with the smallest crystallographic disorder, possessing the highest charge carrier mobility, demonstrate the 

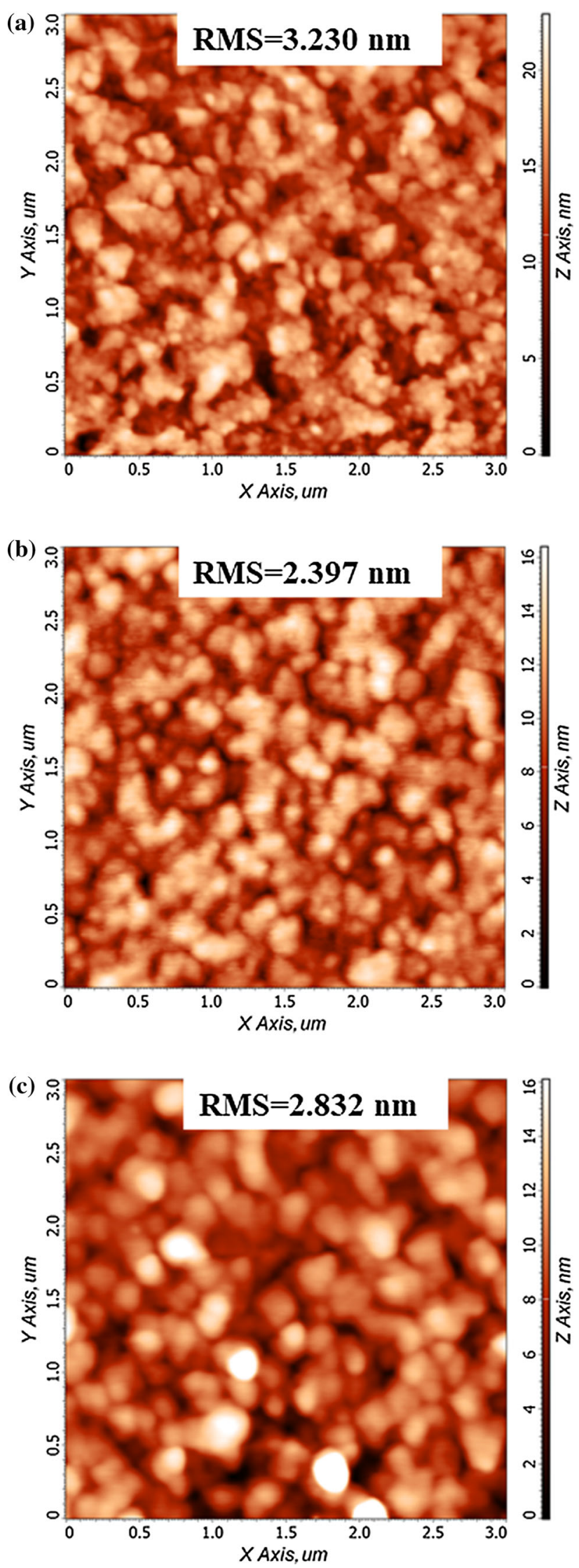

Fig. 4. AFM surface images of ITO substrate (a) and $\mathrm{TiO}_{2} / \mathrm{ITO}$ photoanodes: film thickness $d=50 \mathrm{~nm}$ (b) and $d=280 \mathrm{~nm}$ (c).
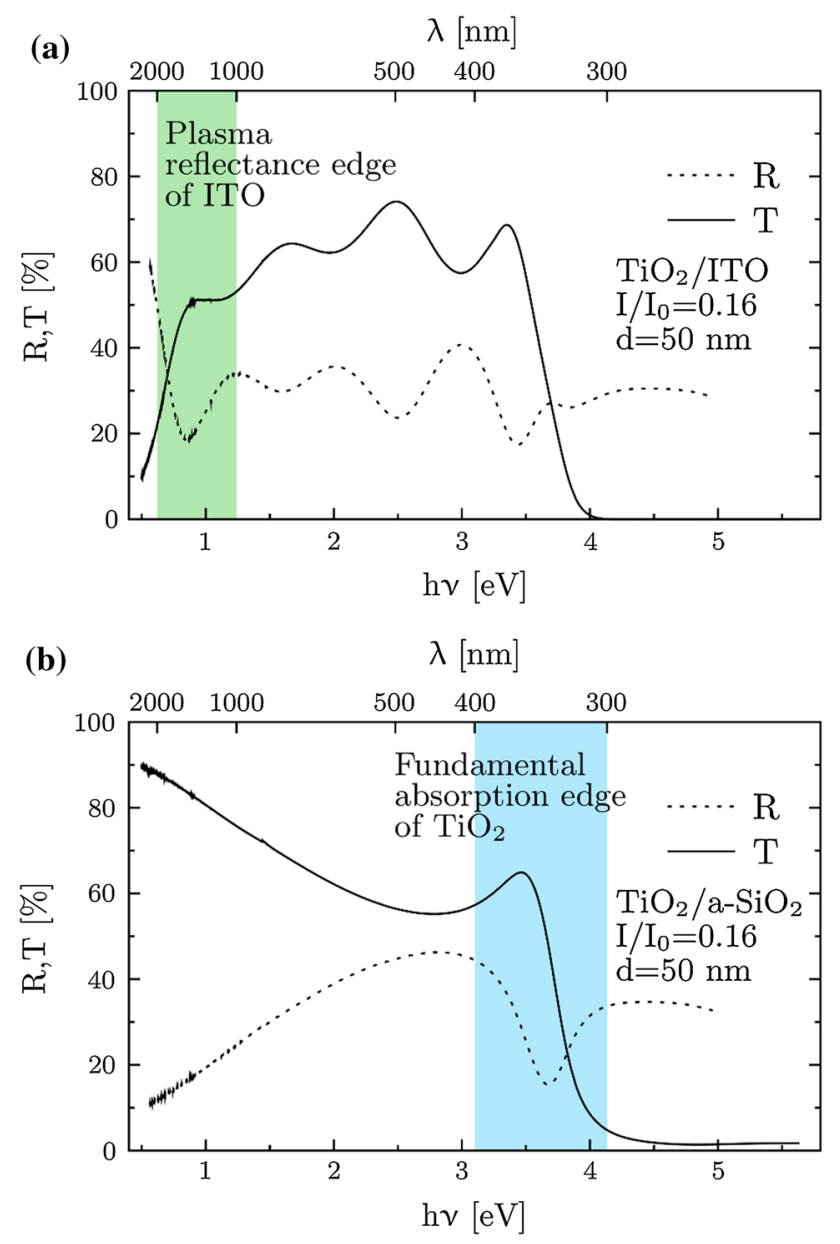

Fig. 5. Spectral dependence of optical transmittance and reflectance of $\mathrm{TiO}_{2} / \mathrm{ITO}(\mathrm{a})$ and $\mathrm{TiO}_{2} / \mathrm{a}-\mathrm{SiO}_{2}$ photoanode (b).

best photocurrent-voltage characteristics and the most negative flat band potential.

Figure 8 summarizes the results obtained in the course of this work. The photocurrent $I_{\mathrm{ph}}$ values at $V_{\mathrm{B}}=0 \mathrm{~V}$ have been found to be correlated with the electrical resistivity $\rho$ of $\mathrm{TiO}_{2} / \mathrm{ITO}$ photoanode. As a general conclusion, one can state that the lower the value of the electrical resistivity, the higher the value of the photocurrent. However, the contribution of the charge carrier concentration and mobility to the photocurrent dependence on the electrical resistivity is different. In the case of stoichiometric thin films of $\mathrm{TiO}_{2}$ deposited at $I / I_{0}=0.16$ onto ITO substrates, the increasing film thickness is accompanied by the improved crystallographic ordering and the increased charge carrier mobility (Fig. 2, Table I). The photocurrent increase in this case can be explained by a substantial improvement of the charge carrier mobility. In the case of nonstoichiometric $\mathrm{TiO}_{2-x}$ thin films of the same thickness, the charge carrier concentration increase is not sufficient to bring the photocurrent to the required level. The charge carrier mobility in the case of nonstoichiometric thin films of $\mathrm{TiO}_{2}$ deposited at $I / I_{0}=0.20$ onto ITO 
Table I. Basic parameters of $\mathrm{TiO}_{2}$ thin films on ITO substrate

\begin{tabular}{|c|c|c|c|c|c|c|c|}
\hline \multirow[b]{2}{*}{$I / I_{0}$} & \multirow[b]{2}{*}{$d(\mathbf{n m})$} & \multirow[b]{2}{*}{$\rho(\Omega \cdot \mathrm{cm})$} & \multirow[b]{2}{*}{$N \cdot 10^{\mathbf{1 8}}\left(\mathrm{cm}^{-\mathbf{3}}\right)$} & \multicolumn{2}{|c|}{$V_{F B}(V)$ from } & \multirow[b]{2}{*}{$\mu\left(\mathrm{cm}^{2} \mathrm{~V}^{-1} \mathrm{~s}^{-1}\right)$} & \multirow[b]{2}{*}{$E_{\mathrm{g}}(\mathrm{eV})$} \\
\hline & & & & $I-V$ & $M-S$ & & \\
\hline \multicolumn{8}{|l|}{$\mathrm{TiO}_{2}$} \\
\hline \multirow[t]{3}{*}{0.16} & 50 & 14,000 & 8.10 & -0.52 & -0.72 & $5.50 \times 10^{-5}$ & 3.54 \\
\hline & 140 & 9618 & 0.73 & -0.72 & -0.81 & $8.85 \times 10^{-4}$ & 3.42 \\
\hline & 280 & 3920 & 0.69 & -0.62 & -0.79 & $2.29 \times 10^{-3}$ & 3.41 \\
\hline \multirow[t]{2}{*}{0.20} & 50 & 3337 & 12.48 & -0.51 & -0.74 & $1.50 \times 10^{-4}$ & 3.63 \\
\hline & & & & & & & \\
\hline 110 & 250 & $5.75 \times 10^{-3}$ & $\begin{array}{c}702 \\
1397^{\mathrm{a}}\end{array}$ & & & $\begin{array}{l}1.54 \\
0.78\end{array}$ & 4.11 \\
\hline
\end{tabular}

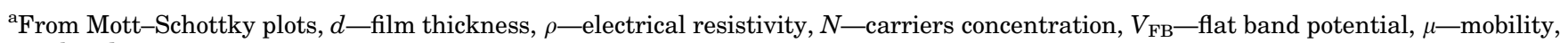
$E_{\mathrm{g}}$-band gap.

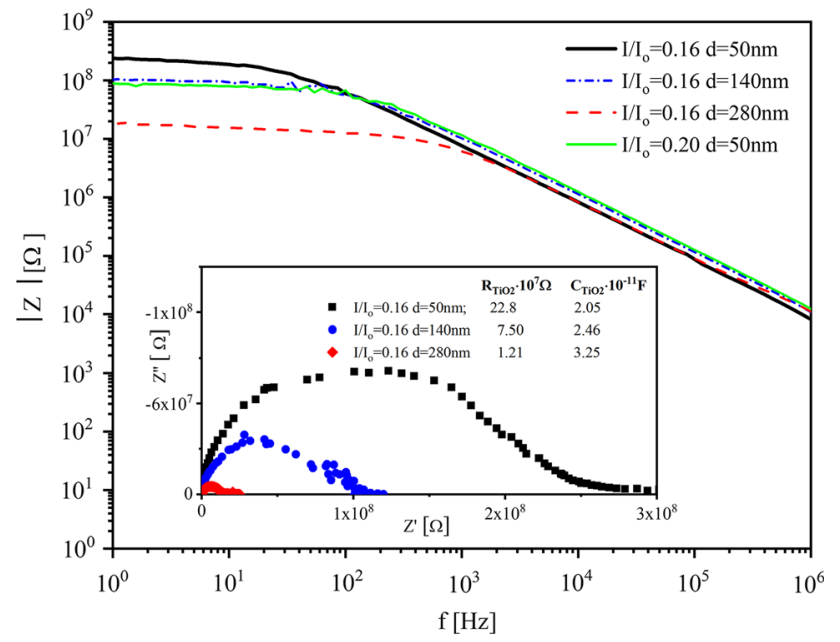

Fig. 6. Impedance spectra of $\mathrm{TiO}_{2} / \mathrm{ITO}$ photoanodes; $|Z|$-absolute value of the impedance; $f$-frequency, $Z$-real, $Z^{\prime}$-imaginary parts of the impedance, $d$-thin film thickness. The inset shows a Nyquist plot.

substrates is lower than that for the stoichiometric ones sputtered at $I / I_{0}=0.16$ as shown in Table I, due to a certain structural disorder accompanied by an increased number of scattering centers.

\section{CONCLUSIONS}

This work was devoted to $\mathrm{TiO}_{2} / \mathrm{ITO}$ photoanodes acting as elements of the integrated solar-driven water splitting devices for hydrogen generation. The importance of the electrical resistivity to the photoelectrochemical processes has been elucidated. It has been demonstrated that the ITO substrate is suitable as a support for thin film metal oxide electrodes, because it does not contribute to the photocurrent under white light illumination. Its transparency over the uv/vis/nir region of the light spectrum combined with the high electrical conductivity fulfills the requirements for the efficient photoanode substrate. As far as $\mathrm{TiO}_{2-x}$ thin films

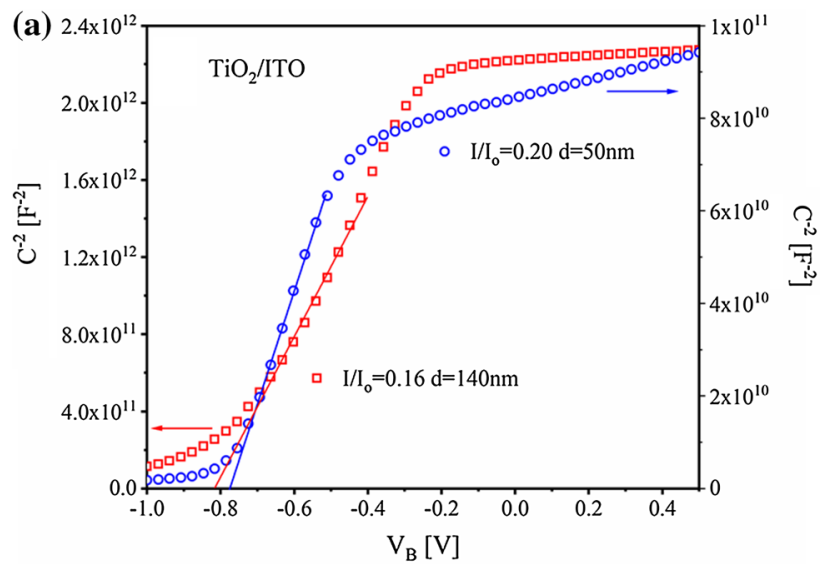

(b)

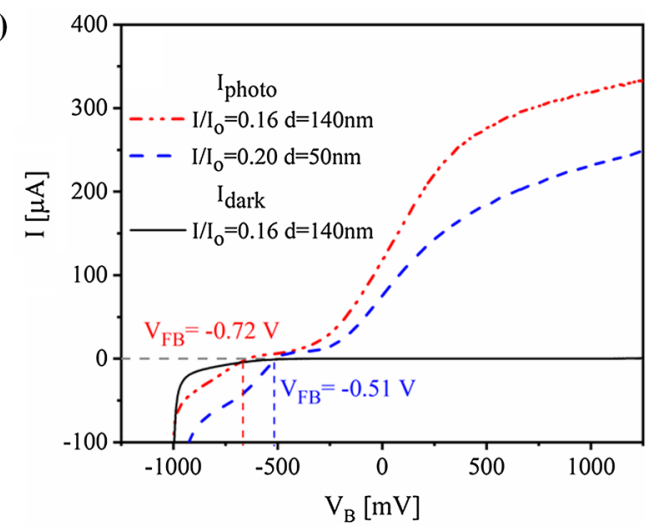

Fig. 7. Characterization of $\mathrm{TiO}_{2} / \mathrm{ITO}$ photoanodes: Mott-Schottky plot (a) and current versus voltage dependence (b).

deposited by dc magnetron sputtering are concerned, it has been found that their thickness was correlated with the charge carrier mobility, $\mu$ while the increased departure from stoichiometry $x$ resulted in the elevated charge carrier concentration, $N$. The photocurrent increase with the film thickness has been attributed to an increased 


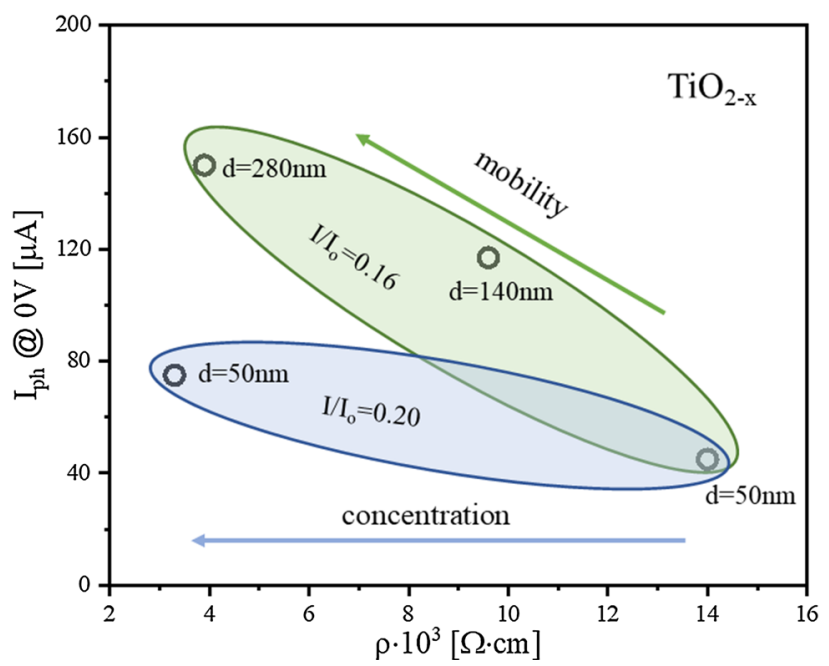

Fig. 8. Photocurrent $I_{\text {ph }}$ versus electrical resistivity $\rho$ of $\mathrm{TiO}_{2} / \mathrm{ITO}$ photoanodes.

charge carriers' mobility and improved film ordering. On the other hand, the film non-stoichiometry leading to the elevated charge carrier concentration creates the crystallographic disorder that reduces partly the growth of the photocurrent.

\section{ACKNOWLEDGMENTS}

KK and AK have been partly supported by the EU Project POWR.03.02.00-00-I004/16. MR (Faculty of Materials Science and Ceramics) and KZ (Faculty of Computer Science, Electronics and Telecommunications) acknowledge the financial support of the Polish Ministry of Science and Higher Education within the framework of subvention for science in 2019.

\section{OPEN ACCESS}

This article is distributed under the terms of the Creative Commons Attribution 4.0 International License (http://creativecommons.org/licenses/by/4.0/ ), which permits unrestricted use, distribution, and reproduction in any medium, provided you give appropriate credit to the original author(s) and the source, provide a link to the Creative Commons license, and indicate if changes were made.

\section{REFERENCES}

1. A. Fujishima and K. Honda, Nature 238, 37 (1978).

2. A. Brudnik, A. Gorzkowska-Sobas, E. Pamula, M. Radecka, and K. Zakrzewska, J. Power Sources 173, 774 (2007).

3. M. Radecka, M. Rękas, A. Trenczek-Zając, and K. Zakrzewska, J. Power Sources 181, 46 (2008).

4. M. Radecka, A. Kusior, A. Trenczek-Zajac, and K. Zakrzewska, Adv. Inorg. Chem. 72, 145 (2018).

5. A. Kusior, A. Wnuk, A. Trenczek-Zając, K. Zakrzewska, and M. Radecka, Int. J. Hydrogen Energy 40, 4936-4944 (2015).

6. J. Li and N. Wu, Catal. Sci. Technol. 5, 1360 (2015).

7. Y. Ma, X. Wang, Y. Jia, X. Chen, H. Han, and C. Li, Chem. Rev. 114, 9987 (2014).

8. H. Ahmad, S.K. Kamarudin, L.J. Minggu, and M. Kassim, Renew. Sustain. Energy Rev. 43, 599 (2015).
9. J. Schneider, M. Matsuoka, M. Takeuchi, J. Zhang, Y. Horiuchi, M. Anpo, and D.W. Bahnemann, Chem. Rev. 114, 9919 (2014).

10. W. Fang, M. Xing, and J. Zhang, J. Photochem. Photobiol., C 32, 21 (2017).

11. R. Shwetharani, M. Sakar, C.A.N. Fernando, V. Binas, and R.G. Balakrishna, Catal. Sci. Technol. 9, 12 (2019).

12. S. Shen, J. Chen, M. Wang, X. Sheng, X. Chen, X. Feng, and S.S. Mao, Prog. Mater Sci. 98, 299 (2018).

13. F. Cao, J. Xiong, F. Wu, Q. Liu, Z. Shi, Y. Yu, X. Wang, and L. Li, ACS Appl. Mater. Interfaces. 8, 12239 (2016).

14. C. Stanley, A. Mojiri, and G. Rosengarten, Nanophotonics 5, 161 (2016).

15. C. Xiang, A.Z. Weber, S. Ardo, A. Berger, Y. Chen, R. Coridan, K.T. Fountaine, S. Haussener, S. Hu, R. Liu, N.S. Lewis, M.A. Modestino, M.M. Shaner, M.R. Singh, K. Sun, and K. Walczak, Angew. Chem. 55, 2 (2016).

16. V. Smirnov, K. Welter, F. Finger, F. Urbain, J.R. Morante, B. Kaiser, and W. Jaegermann, Photoelectrochemical Solar Cell, ed. N.D. Sankir and M. Sankir (Beverly: Scrivener Publishing, 2019), p. 351.

17. Harry L. Tuller, Mater. Renew. Sustain Energy 6, 3 (2017).

18. J. Jia, L.C. Seitz, J.D. Benck, Y. Huo, Y. Chen, J. Wei Desmond, T. Bilir, J.S. Harris, and T.F. Jaramillo, Nat. Commun. 7, 13237 (2016). https://doi.org/10.1038/ncomm s13237.

19. E. Verlage, S. Hu, R. Liu, R.J.R. Jones, K. Sun, C. Xiang, N.S. Lewis, and H.A. Atwater, Energy Environ. Sci. 8, 3166 (2015).

20. R. van de Krol and M. Grätzel, Photoelectrochemical Hydrogen Production (New York: Springer, 2012).

21. K. Zakrzewska, K. Kollbek, M. Sikora, C. Kapusta, J. Szlachetko, M. Sitarz, M. Ziąbka, and M. Radecka, Int. J. Hydrogen Energy 40, 815 (2015).

22. A. Trenczek-Zając, E. Pamuła, M. Radecka, K. Kowalski, A. Reszka, A. Brudnik, E. Kusior, and K. Zakrzewska, J. Nanosci. Nanotechnol. 12, 4703 (2012).

23. M. Radecka, K. Zakrzewska, M. Wierzbicka, A. Gorzkowska, and S. Komornicki, Solid State Ionics 157, 379 (2003).

24. R.G. Breckenridge and W.R. Hosler, Phys. Rev. 91, 793 (1953).

25. R. Dannenberg and P. Green, Thin Solid Films 360, 122 (2000).

26. D. Mardare and G.I. Rusu, Mater. Sci. Eng., B 75, 68 (2000).

27. V. Lionas, T. Georgakopoulos, N. Todorova, S. Karapati, K. Pomoni, and C. Trapalis, Mater. Sci. Semicond. Process. 83, 63 (2018).

28. A. Yildiz, S.B. Lisesivdin, M. Kasap, and D. Mardare, J. Non-Cryst. Solids 354, 4944 (2008).

29. M. Kneiss, M. Jenderka, K. Brachwitz, M. Lorenz, and M. Grundmann, Appl. Phys. Lett. 105, 062103 (2014).

30. K. Pomoni, M.V. Sofianou, T. Georgakopoulos, N. Boukos, and C. Trapalis, J. Alloys Compd. 548, 294 (2013).

31. A. Yildiz, N. Serin, M. Kasap, T. Serin, and D. Mardare, J. Alloys Compd. 493, 227 (2010).

32. G. Gu, Z. He, Y. Tao, Y. Li, J. Li, H. Yin, W. Li, and Y. Zhao, Vacuum 70, 17 (2003).

33. D. Dorow-Gerspach and M. Wuttig, Thin Solid Films 669, 1 (2019).

34. M. Radecka, K. Zakrzewska, H. Czternastek, T. Stapiński, and S. Debrus, Appl. Surf. Sci. 65, 227 (1993).

35. B.-S. Jeong, D.P. Norton, and J.D. Budai, Solid-State Electron. 47, 2275-2278 (2003).

36. A. Trenczek-Zając, M. Radecka, K. Zakrzewska, A. Brudnik, E. Kusior, S. Bourgeois, M. Marco de Lucas, and L. Imhoff, J. Power Sources 194, 93 (2009).

37. K. Krówka, A. Wiatrowski, and W.M. Posadowski, Thin Solid Films 520, 4127 (2012).

38. K. Zakrzewska, A. Brudnik, M. Radecka, and W. Posadowski, Thin Solid Films 343-344, 152 (1999).

39. K. Zakrzewska, Adv. Mater. Sci. Eng. (2012). https://doi.org/ $10.1155 / 2012 / 826873$. 
40. A. Brudnik, H. Czternastek, K. Zakrzewska, and M. Jachimowski, Thin Solid Films 199, 45 (1991).

41. K. Zakrzewska, Titanium Dioxide Thin Films for Gas Sensors and Photonic Applications, AGH Uczelniane Wydawnictwa Naukowo-Dydaktyczne, Kraków 2003, Rozprawy Monografie 115, ISSN 0867-6631.

42. H. Koseoglu, F. Turkoglu, M. Kurt, M.D. Yaman, F.G. Akca, G. Aygun, and L. Ozyuzer, Vacuum 120, 8 (2015)

43. M. Losurdo, M. Giangregorio, P. Capezzuto, G. Bruno, R. De Rosa, F. Roca, C. Summonte, J. Pla, and R. Rizzoli, J. Vac. Sci. Technol., A 20, 37 (2002).
44. H. Kim, C.M. Gilmore, A. Piqué, J.S. Horwitz, H. Mattoussi, H. Murata, Z.H. Kafafi, and D.B. Chrisey, J. Appl. Phys. 86, 6451 (1999).

45. P. Drude, Ann. Phys. 306, 566 (1900).

46. T. Ohsaka, F. Izumi, and Y. Fujiki, J. Raman Spectrosc. 7, 321 (1978).

Publisher's Note Springer Nature remains neutral with regard to jurisdictional claims in published maps and institutional affiliations. 